\title{
Axial length evaluation of eye ball by magnetic resonance imaging in Odisha population
}

\author{
Mohapatra M. ${ }^{1}$, Swain B. ${ }^{2}$, Sahoo R. K. ${ }^{3}$, Manoj K. ${ }^{4}$ \\ ${ }^{1}$ Dr. Manoranjan Mohapatra, Associate Professor, ${ }^{2}$ Dr. Bikramaditya Swain, Assistant Professor, ${ }^{3}$ Dr. Ranjan Kumar \\ Sahoo, Associate Profesor, ${ }^{4}$ Dr. Manoj Kumar, Junior Resident. All authors are affiliated with Department of Radiology, \\ Kalinga Institute of Medical Science, Bhubaneswar, Odisha, India.
}

Corresponding Author: Dr. Ranjan Kumar Sahoo, Associate Professor, Department of Radiology, Kalinga Institute of Medical science, Bhubaneswar, Odisha, India. E-mail- darierdarier2000@gmail.com

\begin{abstract}
Background and Objective: The ocular axial length (AL) changes in refractive errors, ocular, orbital and systemic diseases. Magnetic resonance imaging provides an accurate ocular biometry. Early diagnosis of change of ocular axial length is important to prevent visual compromise. Present study is undertaken to determine the axial length of both eye balls by use of magnetic resonance imaging and to find out possible association between the ocular axial length with age and sex of healthy individuals. Methods: Retrospective study of ocular axial length was carried out in our institution. About 200 numbers of cases with normal MRI findings of brain and orbit were retrospectively analyzed by two senior radiologists independently keeping in view of inter observer variability. Study included T2 weighted axial imaging of brain and orbit from January 2017 to June 2019. Result: The normal axial length of the right and left globe of male person are $23.16 \pm 0.840 \mathrm{~mm}$ and $23.139 \pm 0.830$ respectively. The normal axial length of the right and left globe of female person are $22.55 \pm 0.839 \mathrm{~mm}$ and $22.55 \pm 0.514$ respectively. Male cases have slight higher ocular axial length than female individuals and the difference is statistically insignificant. Conclusion: The normal ocular axial dimension will help the clinician and radiologist to quantitatively evaluate patients with abnormal ocular size and/or refractive errors.
\end{abstract}

Keyword: Axial, length, Eye, Magnetic resonance imaging

\section{Introduction}

Cataract extraction and artificial intraocular lens (IOL) implantation is the most commonly done procedure nowadays. Accurate assessment and calculation of IOL power is essential for desired post-operative refraction. Axial length, corneal curvature and anterior chamber depth data are required for accurate intraocular lens power calculations. In highly myopic adult patients, the axial length continues to increase. Older individuals with posterior staphyloma are more susceptible to having a larger increase in the axial length $[1,2]$.

The size of eye ball changes due to eyeball trauma, cancer, congenital glaucoma, retinoblastoma, and some other disorders. In case of congenital microphthalmos, the eye ball is visibly small. But in borderline cases the distinction between the normal size and the pathologically small size eyeballis difficult for which the normal biometry of eye is essential [3]. The average

Manuscript received: $10^{\text {th }}$ July 2019

Reviewed: $20^{\text {th }}$ July 2019

Author Corrected: $27^{\text {th }}$ July 2019

Accepted for Publication: $31^{\text {st }}$ July 2019 axial length (AL) of newborn's eyeball is about 16 millimeters in diameter which grows slightly to a length of approximately $19 \frac{1}{2}$ millimeters. The large scale studies on the growth of the ocular components suggest that the eye has reached its adult emmetropic axial length by the age of 13 years.In the adult, axial length remains practically unchanged.However, the AL changesin presbyopia especially after the age of 40 [4]. Previous studies in eastern Indian population suggest the axial length of eye ball in emmetropic right and left eye as 23.35 and $23.26 \mathrm{~mm}$ respectively [5].

The axial ocular length varies due to influence of race, ethnicity, and genetics [6]. The AL is an important dimension of eye than other diameters and is larger in myopia and smaller in hypermetropia [7]. Several methods have been described for axial length measurement such as laser doppler interferometry, sonography, computed tomography and magnetic resonance imaging. The sonographic evaluation of eye is operator dependent and requires contact of probe over 
eye and may introduce infection.Computed tomographic evaluation of eye involves ionizing radiation. However, MRI of orbit is safer and accurate modality for evaluation of optic nerve, intraocular and orbital pathology. Axial length of eye ball is an important dimension of all ocular biometry. AL is measured at the level in lens in magnetic resonance imaging (MRI) objectively form anterior to posterior pole. MRI of orbits provides accurate axial length as compared to A- scan ultrasonography. Axial length measurements with MRI match reliably with axial lengths measured by Ascan ultrasonography [8].

There is no standard normative reference data of $\mathrm{AL}$ in eastern Indian population especially people of Odisha. We carried out this retrospective study to obtain the normative data of $\mathrm{AL}$ and to find out any sexual dimorphism.

\section{Subjects and Methods}

Setting of the study: This study was done in Department of Radiology, Kalinga Institute of Medical Science, KIIT university, Bhubaneswar, Odisha. Kalinga Institute of industrial technology (KIIT) university is a large private university in Odisha.

Duration and type of study: Thisretrospective study was performed by analyzing MRI data storage in Department of Radiology from January 2017 to June 2019.

Sampling methods: Data were collected by consecutive sampling from image data storage of Picture Archiving and Communication system (PACS) of thehospital.

Sample size and calculation; Out of 250 cases, 200 cases of MRI examinations were included in study with age range of 10 to 80 years old.

Inclusion Criteria: MRI studies with good image quality are included with no history of ophthalmic pathology or refractory error.

Exclusion Criteria- About 50 studies were discarded due to motion artifact and asymmetric axial images.

Date collection procedure: T2- weighted spin echo sequences in the axial plane were studied. T2- weighted axial images were used for all ocular measurements at lens level. The ALof the eyes was obtained at lens level from posterior aspect of corneal apex to posterior globe wall-fat interface (Figure 1). Image analysis of MRI brain and orbits was done by two senior radiologists and AL evaluation was done by the average of measurements determined by both radiologists.

Data analysis: Statistical analysis was done in SPSS software version 22.0 for Microsoft Window. Values were expressed in terms of the mean and standard deviation (SD).. Correlation between different parameters was tested by Pearson correlation test. The $P<0.05$ is considered statistically significant. Ethical consideration \& permission: Ethical committee permission was not needed for this study due to retrospective non-interventional nature of study as per institutional research board decision.

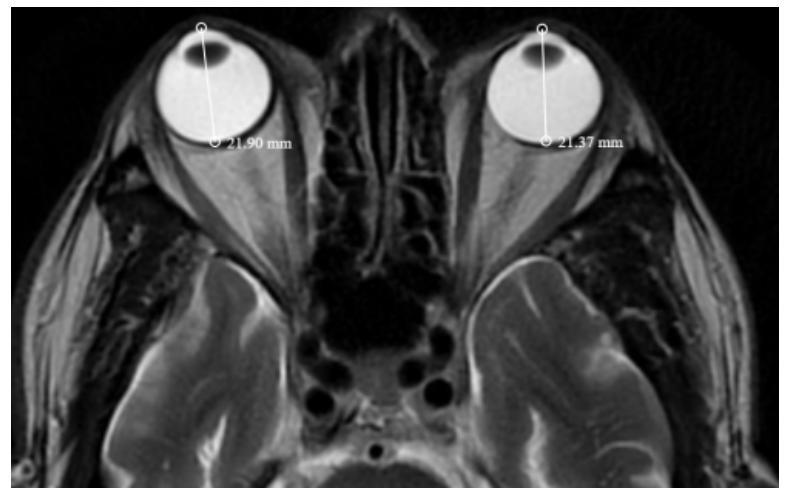

Figure-1: T2-Weighted axial MR image at the level of the lens demonstrates the method of measurement of axial length of the right and left eye ball. 


\section{Results}

Retrospective study of individuals with normal study of MRI head and/orbits was done. Total 400 globes of 200 individuals with age ranging from 10 to 80 were studied. The mean age of individuals was $49.39 \pm 6.95$ years. One hundred twenty $(60 \%)$ of the cases were males while eighty $(40 \%)$ were females. The mean AL of the right globe was $22.91 \pm 0.891 \mathrm{~mm}$, while that of the left was $22.73 \pm 0.88$. The right and left globes paired samples correlation and paired samples test showed no statistically significant differences between right and left globes [Table-1]. Age wise distribution of AL of right and left eye ball is shown in Table-2. There was no statistical significant correlation between age, right and left eye ball axial length [Table-3]. There is no significant difference of AL between right and left eye ball ( $\mathrm{P}=0.41)$. The male individuals have more AL of eye ball than female individual and the difference is not statistically significant. [Table-4].

Table-1: Difference in right and left eye ball $\mathrm{AL}$

\begin{tabular}{|c|c|}
\hline Parameters & Mean \pm deviation \\
\hline RAD & $22.91 \pm 0.891$ \\
\hline LAD & $22.73 \pm 0.88$ \\
\hline p-value & 0.41 \\
\hline
\end{tabular}

Table-2: The means and standard deviations of the right and left globe axial lengths by age groups

\begin{tabular}{|c|c|c|c|}
\hline Age groups & N & $\begin{array}{c}\text { RAD (mm) } \\
\text { Mean } \pm \text { SD }\end{array}$ & $\begin{array}{c}\text { LAD (mm) } \\
\text { Mean } \pm \text { SD }\end{array}$ \\
\hline$\leq 19$ years & 14 & $22.29 \pm 0.954$ & $22.28 \pm 0.708$ \\
\hline $20-39$ years & 46 & $22.94 \pm 0.978$ & $22.9 \pm 0.963$ \\
\hline $40-59$ years & 69 & $22.89 \pm 0.865$ & $22.95 \pm 0.885$ \\
\hline$\geq 60$ years & 71 & $23.052 \pm 0.779$ & $23.06 \pm 0.792$ \\
\hline
\end{tabular}

Table-3: Correlation of age with the right and left globes axial length

\begin{tabular}{|c|c|c|}
\hline Parameters & Coefficient of correlations (r) & P value \\
\hline RAD & 0.143 & 1.9 \\
\hline LAD & 0.171 & 2.08 \\
\hline
\end{tabular}

Table-4:The means and standard deviations of the globes' axial lengths by gender

\begin{tabular}{|c|c|c|c|c|}
\hline Parameter & Male N-120 & Female N-80 & Mean difference & P value \\
\hline & Mean \pm SD & Mean \pm SD & & $<0.001$ \\
\hline Age & $54.35 \pm 18.121$ & $44.48 \pm 20.04$ & 9.87 & 1.6 \\
\hline RAD $(\mathrm{mm})$ & $23.161 \pm 0.840$ & $22.55 \pm 0.839$ & 0.606 & 1.6 \\
\hline LAD $(\mathrm{mm})$ & $23.139 \pm 0.830$ & $22.55 \pm 0.514$ & 0.639 & \\
\hline
\end{tabular}

\section{Discussion}

The first edition of Henery Gray's "Anatomy: Descriptive and Surgical" of 1858 mentioned that "the axial length of the eyeball measures about an inch and exceeds the transverse diameter by about a line" [9]. In 1912, the average measurements of the eye ball diameters were accepted by various authors were
$24.26 \mathrm{~mm}$ for the anteroposterior diameter [10]. In 1970, it was known that axial length differs in cases with myopia $(24.61 \pm 1 \mathrm{~mm})$, emmetropia $(23.40 \pm 1.38 \mathrm{~mm})$, and hypermetropia $(22.53 \pm 1.02 \mathrm{~mm})$ [11]. It is a general statement by the manuals of ophthalmology thatthe eyeball diameter differs among adults by only one or 
two millimeters [12]. The AL of the globe is the distance from the corneal apex to the retinal pigment epithelium/Bruch's membrane [13]. Among Odisha population, the mean ocular $\mathrm{AL}$ was found to be $22.82 \pm 0.886$. Nangia et al studied the AL of globe by use of ultrasonic biometric method in rural Central India with mean age $49.4 \pm 13.4$ years and found the mean AL as $22.6 \pm 0.91 \mathrm{~mm}$ which is similar to the present study [14]. George et al. also showed similar mean AL value $(22.28 \pm 0.8 \mathrm{~mm})$ as obtained in the present study [15].

However He M etal. [16] and Wickremasinghe et al. [17] conducted study in South China and Rural Mongolia respectively and found the AL value as 23.11 and $23.1 \mathrm{~mm}$ which are larger than the present study.

Beaver Dam Eye Study by Lee et al [18] and Epic EPIC-Norfalk eye study by Foster et al. [19] study in England showed the mean AL as 23.69 and 23.80 respectively. Huang Q et al carried out ocular biometry in western china by partial coherence laser interferometry in patient with 50 and above age with cataract and shows the average AL as $24.32 \pm 2.42 \mathrm{~mm}$ [20]. Bikbov MM et al. conducted study in Russian population and shows the average AL of eye ball is similar to Beijing and Singaporean population [21]. The difference of AL measurement in all above studies could be due to racial variation and environment influence [6].

Detorakis et al. [22] did not find any statistically significant difference between data for the right and left globes. Salaam et al reported no significant difference of AL between globes in their sonographic evaluation of eyes in Nigeria population [23].

There is no significant difference in right and left eye ball AL in the present study. Some studies shows sexual dimorphism with males having higher values than females $[25,26]$. In the study done by Akduman EIet al [6], the AL of the right globe in males was $23.51 \pm 1.35 \mathrm{~mm}$ while that of the females was $22.93 \pm$ $1.35 \mathrm{~mm}(\mathrm{P}=0.008)$, and the mean $\mathrm{AL}$ of the left globe among males was $23.54 \pm 1.23 \mathrm{~mm}$ compared to $22.79 \pm$ $1.04 \mathrm{~mm}$ for females $(\mathrm{P}<0.001)$. In the present study, the $\mathrm{AL}$ of the right globe in males was $23.161 \pm 0.840$ $\mathrm{mm}$ while that of the females was $22.55 \pm 0.839 \mathrm{~mm}$ $(\mathrm{P}=1.6)$, and the mean $\mathrm{AL}$ of the left globe among males was $23.193 \pm 0.830 \mathrm{~mm}$ compared to $22.55 \pm 0.514$ $\mathrm{mm}$ for females $(\mathrm{P}=1.6)$. However study conducted by Albashir SI, et al. showed statistically significant higher axial eye ball length in male than female [25]. In the present study, there was no correlation between participants' age and the ocular AL. The studies conducted by Lee et al[18] (Beaver Dam Eye Study) and Wong et al [25]. (Tanjong-Pagar study) showed that the AL decreased with increasing age while a central Indian Eye and Medical Study by Nangia et al [14] showed that the AL increased with increasing age. Similar observation was also noted by Wickremasinghe et al [17].

The contrast observed between our findings and that of these authors may be due to racial variations, environmental influences and/or technique employed in the studies. One cross sectional observational eastern Indian study done by Roy et al in 152 cases showed the mean AL in emmetropic right and left eye as 23.35 and $23.26 \mathrm{~mm}$ with no statistical significant sexual dimorphism [5]. The above study is showing similar observation as found in the present study. In contrast, the study done in Latinos by Shufelt et al. revealed the average AL was $23.38 \mathrm{~mm}$, with a range of 18.7 to 33.8 $\mathrm{mm}$ in the women (mean, $23.18 \mathrm{~mm}$ ) and 20.7 to 34.5 $\mathrm{mm}$ in males (mean, $23.65 \mathrm{~mm}$ ). The difference between the men and women was significant [26].

Limitations of the study: The sample size is smaller. A large prospective study is needed for better normative date and statistical analysis. All the case should be screened by ophthalmologist to rule out refractive errors and other ocular abnormality before inclusion of in the study. Thinner slice and volumetric MRI data image of eye ball should be obtained in MRI scanner for accurate assessment of ocular biometry.

\section{Conclusion}

AL of globe with males having slight higher values than female which is statistically insignificant. The mean AL obtained in this study is matching with the study of central India and differs from the values obtained in China and Britain which further confirms that racial variation and environmental influences affect the AL of the globe as supported by other studies also.This normative data will help the ophthalmologist, clinician and radiologists for better evaluation of ocular pathology.

\section{What this study adds to existing knowledge?}

This study will help radiologist and ophthalmologist for assessment of refractive error, congenital microphthalmia, prognostication of high grade myopia and retinal detachment and other ophthalmological disorder in Odisha population as there is no normative data of ALof orbit in population of Odisha. 


\section{Authors' Contributions}

Dr. Manoranjan Mohapatra: Preparation of the manuscript and revision of work.

Dr. Bikramaditya Swain: Editing of the manuscript.

Dr. Ranjan Kumar Sahoo: Conceived the original idea and preparation of the manuscript.

Dr. Manoj Kumar G: Involved in manuscript preparation, drafting and critically revising the work.

Funding: Nil, Conflict of interest: Nil

Permission from IRB: Yes

\section{References}

1. Verhulst E, Vrijghem JC. Accuracy of intraocular lens power calculations using the Zeiss IOL master. A prospective study. Bull Soc Belge Ophtalmol. 2001; 281(281):61-5.

2. Saka N, Ohno-Matsui K, Shimada N, Sueyoshi SI, Nagaoka N, Hayashi W, Hayashi K, Moriyama M, Kojima A, Yasuzumi K, Yoshida T. Long-term changes in axial length in adult eyes with pathologic myopia. Am. J. Ophthalmol 2010;150(4):562-8.doi: https://doi. org/ 10.1016/j.ajo.2010.05.009

3. Bekerman I, Gottlieb P, Vaiman M. Variations in eyeball diameters of the healthy adults. J Ophthalmol. 2014;2014. doi: http://dx.doi.org/10.1155/2014/503645

4. Bhardwaj V, Rajeshbhai GP. Axial length, anterior chamber depth-a study in different age groups and refractive errors. J Clin Diagn Res. 2013;7(10):2211. doi: 10.7860/JCDR/2013/7015.3473.

5. Roy A, Kar M, Mandal D, RAy RS, Kar C. Variation of axial ocular dimensions with age, sex, height, BMIandtheir relation to refractive status. J Clin Diagn Res. 2015;9(1):AC01.doi: 10.7860/ JCDR/2015/ 10555. 5445

6. Hashemi H, Khabazkhoob M, Miraftab M, Emamian MH, Shariati M, Abdolahinia T, Fotouhi A. The distribution of axial length, anterior chamber depth, lens thickness, and vitreous chamber depth in an adult population of Shahroud, Iran. BMC Ophthalmol. 2012; 12(1): 50.doi: 10.1186/1471-2415-12-50

7. Wang FR, Zhou XD, Zhou SZ. A CT study of the relation between ocular axial biometry and refraction. [Zhonghuayankezazhi] Chin J of Ophthalmol. 1994;30 (1): 39-40.
8. Akduman EI, Nacke RE, Leiva PM, Akduman L. Accuracy of ocular axial length measurement with MRI. Ophthalmologica.2008;222(6):397-9.doi:https://doi.org /10. 1159/000153419.

9. H. Gray, Anatomy Descriptive and Surgical,JohnW. Parkerand Son, London, UK, 1858.

10. M. Salzmann, The Anatomy and Histology of the Human Eyeball in the Normal State, Its Development and Senescence, The University of Chicago Press, Chicago, Ill, USA, 1912.

11. Tomlinson A, Phillips CI. Applanation tension and axial length of the eyeball. The B JOphthalmol. 1970; 54 (8): 548.doi: 10.1136/bjo.54.8.548.

12. J.C.Tsai,A.K.O.Denniston,P.I.Murray, andJ.J.Huang, Eds., Oxford American Handbook of Ophthalmology, Oxford University Press, Oxford, UK, 2011.

13. Hitzenberger CK. Optical measurement of the axial eye length by laser Doppler interferometry. Invest Ophthalmol Vis Sci. 1991;32(3):616-24.

14. Nangia V, Jonas JB, Sinha A, Matin A, Kulkarni M, Panda-Jonas S. Ocular axial length and its associations in an adult population of central rural India: the Central India Eye and Medical Study. Ophthalmol.2010;11(7) : 1360-6.doi:https://doi.org/10.1016/j.ophtha.2009.11.040

15. George R, Paul PG, Baskaran M, Ramesh SV, Raju P, Arvind H, McCarty C, Vijaya L. Ocular biometry in occludable angles and angle closure glaucoma: a population based survey. B J Ophthalmol. 2003;87(4): 399-402.doi: http://dx.doi.org/10.1136/bjo.87.4.399

17. He M, Huang W, Li Y, Zheng Y, Yin Q, Foster PJ. Refractive error and biometry in older Chinese adults: the Liwan eye study. Invest Ophthalmol Vis Sci 2009;50(11):5130-6.doi: 10.1167/iovs.09-3455

18. Wickremasinghe S, Foster PJ, Uranchimeg D, Lee PS, Devereux JG, Alsbirk PH, Machin D, Johnson GJ, Baasanhu J. Ocular biometry and refraction in Mongolian adults. Invest Ophthalmol Vis Sci. 2004; 45(3): 776-83.doi:10.1167/iovs.03-0456.

19. Lee KE, Klein BE, Klein R, Quandt Z, Wong TY. Association of age, stature, and education with ocular dimensions in an older white population. Arch Ophthalmol. 2009; 127 (1): 88-93.doi: 10. 1001/ archophthalmol. 2008.52. 


\section{Original Research Article}

20. Foster PJ, Broadway DC, Hayat S, Luben R, Dalzell $\mathrm{N}$, Bingham S, Wareham NJ, Khaw KT. Refractive error, axial length and anterior chamber depth of the eye in British adults: the EPIC-Norfolk Eye Study. Brit J Ophthalmol. 2010;94(7):827-30.doi; http://dx.doi.org /10. 1136/ bjo.2009.163899.

21. Huang Q, Huang Y, Luo Q, Fan W. Ocular biometric characteristics of cataract patients in western China. BMC Ophthalmol. 2018;18(1): 99.doi: https:// doi. org /10. 1186/s12886-018-0770-x

22. Bikbov MM, Kazakbaeva GM, Gilmanshin TR, Zainullin RM, Arslangareeva II, Salavatova VF et al. Axial length and its associations in a Russian population: The Ural Eye and Medical Study. PloS one. 2019; 14(2): e0211186.doi: https://doi.org/10.1371/ journal. pone. 0211186 .

23. Detorakis ET, Drakonaki EE, Papadaki E, Tsilimbaris MK, Pallikaris IG. Evaluation of globe position within the orbit: clinical and imaging correlations. BritJ Ophthalmol. 2010; 94(1):135-6.doi: http://dx.doi.org/ 10.1136/bjo. 2008.150532.
24. Salaam AJ, Aboje OA, Danjem SM, Igoh EO, Salaam AA, Aiyekomogbon JO et al. Sonographic axial length of the eye in healthy Nigerians at the Jos University teaching hospital.doi: http://hdl.handle.net/ $123456789 / 2411$.

25. Albashir SI, Saleem M. Normal range values of ocular axial length in adult Sudanese population. AlBasar Int J Ophthalmol. 2015;3(2):31.doi: 10.4103/ 1858-6538. 172098.

26. Wong TY, Foster PJ, Johnson GJ, Seah SK. Education, socioeconomic status, and ocular dimensions in Chinese adults: the TanjongPagar Survey. Brit J Ophthalmol. 2002;86(9):963-8.doi: http://dx.doi.org/10. 1136/bjo. 86.9.963.

27. Shufelt C, Fraser-Bell S, Ying-Lai M, Torres M, Varma R. Refractive error, ocular biometry, and lens opalescence in an adult population: the Los Angeles Latino Eye Study. Invest Ophthalmol Vis Sci.2005; 46 (12): 4450-60.doi:10.1167/iovs.05-0435

\section{How to cite this article?}

Mohapatra M, Swain B, Sahoo R. K, Manoj K. Axial length evaluation of eye ball by magnetic resonance imaging in Odisha population. Trop J Ophthalmol Otolaryngol.2019; 4(3):233-238.doi:10.17511/jooo.2019.i03.09 